O ver the past two weeks I have spent many hours on the roads in Punjab and North West Frontier Province (NWFP) , visiting district administrations. My promise to write this "letter from Pakistan" has made me think about some of the occupational and environmental health aspects of this rather reckless activity. Since I do this as an integral part of my work, I suppose the significant risk of death or injury it entails could count as occupational. The risk is reduced because drunken driving is not a problem here (although driving under the influence of drugs such as cannabis and opium is reportedly common among truck drivers); but this is more than compensated for by the "macho" culture, whereby normal behaviour is to approach, at speed, the vehicle you want to overtake to within inches, blast your horn and flash your lights, then accelerate past, just making it out of the path of the oncoming truck. And there is always an oncoming truck. Most freight now travels by road instead of rail, with resulting damage to the roads, increasing problems of air pollution in urban areas, and frustrations and hazards for other road users.

Accidents are not the only risk. The tribal areas of the NWFP harbour bands of brigands who commonly hijack vehicles; it's not a good idea to travel the roads adjoining these areas after dark. A senior police officer in one district told us about one of his officers who was kidnapped and released the previous day,

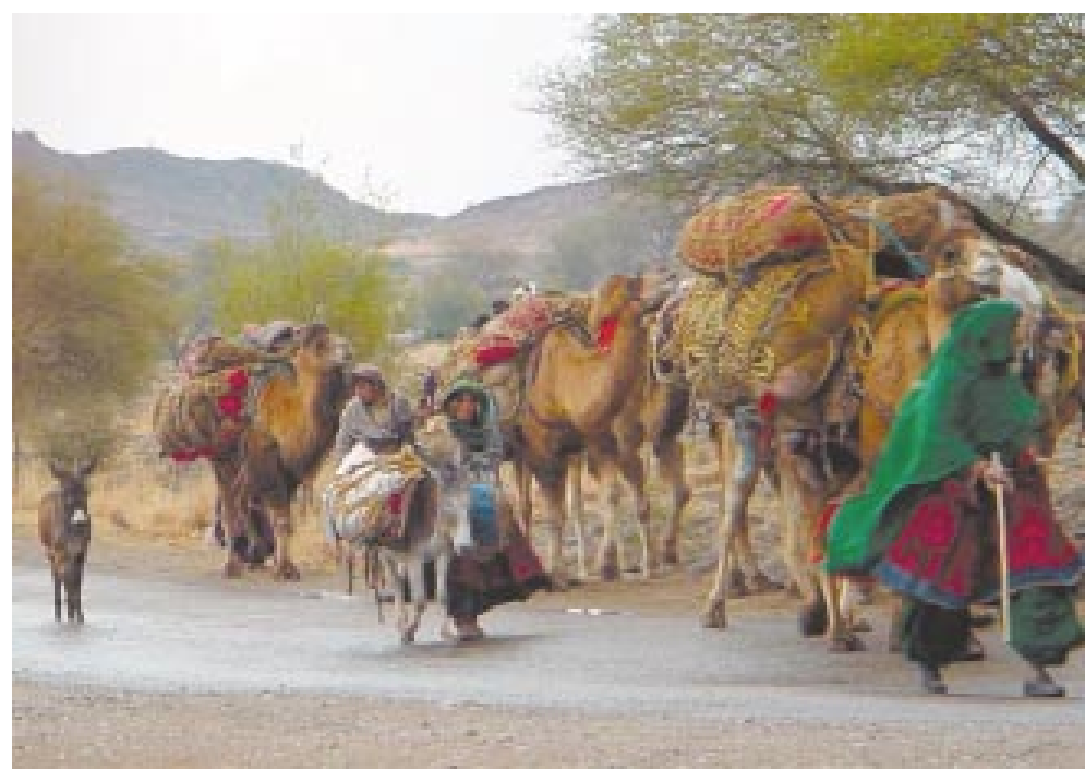

after two weeks, once the gang realised they had mistaken him for someone else. On the grounds of this potential risk of kidnap, we always try to eat a reasonable meal before starting back on the road from such places.

With Eid only a day away, many vehicles today were filled with animals on their way to sacrifice; one cow we passed dashing off up the road, apparently aware of its impending fate. People like to spend the holiday with family in the village, so the roads are full of buses and pick-ups, grossly overloaded with passengers (video 1). A more environmentally friendly, if slower, method of transporting your goods and family is using beasts of burden; camels are quite common, although they can inflict nasty injuries when riled (video 2).

How to reduce these road transport problems? Well, there is clear progress already, with an excellent motorway system taking shape (you pay a toll but it's not much), which disallows overweight vehicles, and is well maintained and well policed. It would help if the railways were improved to encourage more freight to travel by rail. And on a personal level, make sure you have a good driver who avoids the worst excesses, and don't travel too much in the dark if you can avoid it. Beyond that, a strong nerve and trust in a higher power help.

February 2002

Anne Cockcroft Editor, OEM

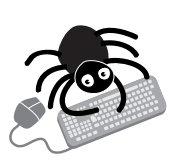

The videos can be viewed on the Occupational and Environmental Medicine website [www.occenvmed.com]

\title{
$\mathrm{ECHO}$
}

\section{Stepping off the treadmill}

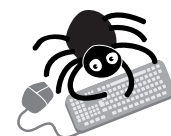

Please visit the Occupational and

Environmental Medicine website [www.occenvmed com] for link to this full article. athology services face serious staff shortages as a major survey of over 400 UK consultant medical microbiologists and virologists discloses that many plan to retire early because of increasing workload and low morale.

The questionnaire survey, endorsed by the Association of Clinical Pathologists, Royal College of Pathologists, and Association of Medical Microbiologists, identified 464 practising consultant medical microbiologists and virologists, $367(79 \%)$ of whom responded.

The responses confirmed anecdotal evidence of increased workload and its effects. Over half of those responding planned to retire early, at or before age 60. A similar proportion was already working more than 48 hours a week or was on call $1: 1$ or $1: 2$ at weekends. Both situations were independently associated with impaired psychological health, and working $1: 1$ or $1: 2$ on call at weekends was also linked to low morale.

The respondents included 33 virologists and a minimum of 89 single handed practitioners. The majority $(60 \%)$ worked in district general hospitals and the rest mostly in teaching hospitals. They were identified from the datasets of their professional bodies; by PHLS regional epidemiologists; and by key people in the health service regions.

Consultant medical microbiologists and virologists have experienced a greater workload, of increasing scope and complexity, particularly over the past five years, against an increase in their numbers of only $12.5 \%$ during 1987-97 compared with $27-105 \%$ in other specialties.

A Journal of Clinical Pathology 2002;86:200-205. 